IJOSES

e-ISSN 2148-8673
Uluslararası Sosyal ve Eğitim Bilimleri Dergisi

International Journal of Social and Educational Sciences

Cilt 6, Sayı 11, Haziran 2019 \& Vol 6, No 11, June 2019

(C2019 Telif Hakkı IJOSES'e aittir
DOI: $10.20860 /$ ijoses.486630

Geliş Tarihi \& Received: 22.11.2018
Makale Türü: Araştırma Makalesi

Kabul Tarihi \& Accepted: 14.06.2019

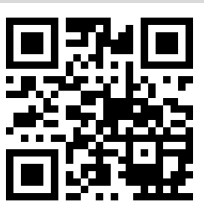

Article Types: Research Article

IJOSES, 2019, 6 (11): 62-74

\title{
Ortaokul Öğrencileri için Matematiğe Yönelik Tutum Ölçeğini Türkçe'ye Uyarlama Çalışması
}

Turkish Adaptation Study of Attitudes towards Mathematics in Secondary School Students

\section{Özgür Şen*}

$\ddot{0} \mathbf{z}$

Bu çalışmada, Yáñez-Marquina \& Villardón-Gallego tarafından geliştirilen Ortaokul Öğrencileri için Matematiğe Yönelik Tutum Ölçeği'nin Türkçe'ye uyarlama çalışması yapılmıştır. Çalışma, 5, 6, 7 ve 8. sınıfta öğrenim gören 878 ortaokul öğrencisinden alınan veriler ile gerçekleştirilmiştir. Açımlayıcı faktör analizi ve doğrulayıcı faktör analizleri uygulanarak ölçeğin yapı geçerliliği incelenmiştir. Ölçeğin özgün formu 19 maddeden oluşmaktadır. Analizler doğrultusunda 1 madde ölçekten çıkarılarak Türkçe'ye uyarlamasında 18 madde yer almıştır. Çalışmanın sonucunda, uyarlaması yapılan ölçeğin faktör yapısı, özgün yapısıyla tutarlı 3 faktörlü (öz benlik, matematiğin algılan kullanışlılığı, ilgi) model oluşturduğu görülmüştür. Doğrulayıcı faktör analizi sonuçları ölçeğin literatürde istenilen uyum indekslerini sağlamaktadır. Güvenirlik çalışmasına göre ölçeğin Cronbach alfa değeri 0.91 olarak hesaplanmıştır. Elde edilen bulgular, uyarlanan ölçeğin ortaokul öğrencilerinin matematiğe yönelik tutumlarını ölçmek için alternatif, kullanışlı, uygulanması kolay, geçerli ve güvenilir bir araç olduğunu göstermiştir.

Anahtar Kelimeler: Ortaokul öğrencileri, ölçek uyarlama, matematik, tutum.

\begin{abstract}
This is a study of adaptation of the Scale for Assessing Attitudes towards Mathematics in Secondary Education (SATMAS) developed by Yáñez-Marquina \& Villardón-Gallego (2016) into Turkish. The study was conducted with data collected from 878 secondary school students. Exploratory factor analysis and confirmatory factor analysis were done so as to analyse the construct validity of the scale. The scale in its original form contained 19 items. In consequence of the analyses, one of the items was removed from the scale and thus the Turkish version of the scale contained 18 items. The factor structure formed a 3-factor model consistent with the original structure of the scale and with its items. Confirmatory factor analysis had the fit indices for the scale demanded in the literature. The Cronbach's Alpha was calculated as 0.91 for the scale. The results obtained demonstrated that the scale was a useful, easy to use, valid and reliable instrument in assessing secondary school students' attitudes towards mathematics.
\end{abstract}

Keywords: Secondary school students, adaptation of scale, mathematics attitude.

\footnotetext{
* (Dr. Öğretim Üyesi); Yozgat Bozok Üniversitesi, senozgur@yahoo.com, ORCID: orcid.org/0000-0002-8177-0984
}

Kaynak Gösterme: Şen, Ö. (2019). Ortaokul Öğrencileri için Matematiğe Yönelik Tutum Ölçeğini Türkçe’ye Uyarlama Çalışması. Uluslararası Sosyal ve Eğitim Bilimleri Dergisi, 6 (11), 62-74. DOI: 10.20860/ijoses.486630 


\section{Extended Summary}

\section{Purpose and Significance:}

A review of relevant literature makes it clear that the number of valid and reliable scales prepared to assess especially secondary school students' attitudes is very small. This study aims to adapt the scale for Assessing Attitudes towards Mathematics in Secondary Education (SATMAS) developed by Yáñez-Marquina \& Villardón-Gallego (2016) into Turkish and to develop a valid and reliable instrument to evaluate secondary school students' attitudes towards mathematics.

The scale in its original from included three factors- namely, 1) self-concept, 2) perceived usefulness of mathematics, and 3) interest. The original scale was developed by administering it to 792 secondary education students whose age was 13.96 on average ( $\mathrm{sd}=1.09)$. the Cronbach's Alpha coefficient for the overall scale was found as .92.

\section{Method}

This study employs survey model, which is one of qualitative research methods. Survey models, which aim to describe a past state or a current state as it is, intend to make a generalization based on the who population or on a group taken from the population (Karasar, 2005). The study included 878 secondary school students $53 \%(n=465)$ of whom were girls and $47 \%(\mathrm{n}=413)$ of whom were boys. Of the participants, $16,9 \%(\mathrm{n}=148)$ were the fifth graders, $31,8 \%(n=279)$ were the sixth graders, $28,7 \%(n=252)$ were the seventh graders and $22,6 \%$ $(n=199)$ were the eighth graders. 320 students' views were consulted for exploratory factor analysis, 344 students' views were consulted for confirmatory factor analysis and 214 students' views were consulted to validate the scale.

Prior to adaptation work, the author was contacted and the necessary permission was obtained for the study. A group of five experts two of whom were educators in mathematics, one of whom was a mathematics teacher and two of whom were trainers in English Language Teaching took part in the adaptation work.

\section{Results}

Following Barlett's sphericity test, $\left[\chi^{2}=3669.296 ; \mathrm{sd}=171 ; \mathrm{p}=0.000<0.1\right]$ was found. According to the data, it was concluded that the scale was appropriate for factor analysis. EFA results indicated that the scale had three factors whose eigenvalues were bigger than 1 - as in its original version. Item 19 was excluded from the analyses since the difference between loads was smaller than 1 (.457-.036). The eigenvalues for the factors were $7.409 ; 2.763$ and 1.815, respectively. The three factors explained $66,59 \%$ of the total variance. Exploratory factor analysis result showed that the structure of the original scale and the adapted scale were fully consistent in the number of factors and in items. Item factor loads ranged between .62 and .84 .

According to confirmatory factor analysis results, the fit indices for the scale were calculated as $\left[\chi^{2}=347.740 ; \mathrm{sd}=132, \mathrm{p}=.000 ; \chi^{2} \div \mathrm{sd}=2.634 ; \mathrm{CFI}=.951 ; \mathrm{GFI}=.902 ; \mathrm{NFI}=.923 ; \mathrm{AGFI}\right.$ $=.873 ;$ RMSEA $=.069]$. Thus, it was found that the three-factor scale confirmed the fit indices necessary for confirmatory factor analysis. 
Item total correlations for the items in the scale ranged between .447 and .812 and the tvalues for the score averages of top $25 \%$ and bottom $25 \%$ groups were significant $(\mathrm{p}<.001)$ for all items. Cronbach's Alpha internal consistency coefficient was calculated as .91 for the whole scale.

\section{Discussion and Conclusion}

It was concluded according to the analysis results that the factor structure and items of the scale in the adaptation version agreed with the ones in the original version. The factors in the scale were self-concept (items 1, 2, 3, 4, 5, 6 and 7); perceived usefulness (items 8, 9, 10, 11 and 12) and interest (items 13, 14, 15, 16, 17 and 18). Considering the reliability and validity evidence of the scale, Yáñez-Marquina \& Villardón-Gallego (2016) state that the scale is a promising instrument in assessing secondary education students' attitudes towards mathematics. This can also be said for the Turkish adaptation of the scale. It may be said that the Turkish version of the scale will contribute to the literature in that it is easy to use, it does not take much time and that the items in the scale are comprehensible. This study demonstrated that the adapted scale was a valid and reliable instrument in assessing secondary school students' attitudes towards mathematics.

\section{Giriş}

İnsan kimliğinin merkezi parçalarından biri tutumdur (Bohner \& Wänke, 2002). Tutum insan, nesne, kavram veya durumlara yönelik olarak olumlu ya da olumsuz yanıt vermek için öğrenilen eğilimlerdir (Yıldız \& Turanlı, 2010). Aslında bir tepki hazırlığı gibi düşünülen tutum bir davranış değil, davranışın ön koşulu olarak tanımlanmaktadır (Ünal, 1981, s.9). Krech \& Crutcfield (1980), tutumu bireyin dünyasındaki bir olaya karşı bilşisel, algısal ve güdüsel süreçlerin kesintisiz devam eden bir örgütlenmesi olduğunu söylemektedir (Akt, Tavşancil, 2010, s. 67). Aynı zamanda, tutum, öğrenmenin temel bileşenlerinden birini oluşturmaktadır. Genel olarak tutumlar olumlu olarak görülürler. Bireylerin duygu, inanç, değer ve davranışlarını kapsayarak öğrenme ve öğretme süreci üzerinde etkili olan düşünme, davranış ve davranış tarzlarını etkilemektedirler (Akinoso, 2017).

Matematik eğitimi için, öğrencilerin matematik dersi ve duyguları ile ortaya çıkan matematiğe yönelik tutumları büyük önem taşımaktadır (Nazlıçiçek \& Erktin, 2002). Ayrıca, öğrencilerin matematik dersi ile ilgili olarak yaşadıkları tecrübeler, matematiğe yönelik olarak olumlu ve olumsuz tutum geliştirmelerine neden olmaktadır (Kocakaya, Okuyucu, Öner \& Uzunyol, 2018). Bu bakımdan, öğrencilerin matematiğe karşı olumlu tutum oluşturma, varolan tutumlarını geliştirme, koruma ve güçlendirmeleri büyük önem taşımaktadır (Sezgin-Memnun, 2015). Matematiğe yönelik tutum, matematiğe olumlu veya olumsuz bir şekilde yanıt verme yatkınlığı olarak tanımlanır (Moenikia \& Zahed-Babelan, 2010). Tutum, matematik öğrenme ve öğretme sürecinde hayati bir rol oynamakla beraber öğrencilerin matematik alanındaki başarılarına etki etmektedir (Farooq \& Shah, 2008). Çocukların matematiğe yönelik tutumları kendi matematiksel yeterliliklerini algılamalarını büyük ölçüde etkilemekte, matematik performansları üzerinde derin bir etki yaratmaktadır (Soni \& Kumari, 2017). Matematiğin pek çok kişi için zor ve algılanması karmaşık bir ders olarak düşünülmesinin, bireylerin matematiğe yönelik tutumlarını etkileyebileceği kaçınılmazdır. Ortaokul matematik dersi öğretim 
programları, öğrencilerin matematiğe özgüvenli bir yaklaşım sergilemelerini aynı zamada olumlu tutum geliştirmelerini amaçlar (MEB, 2009, 20013, 2017).

Tutum, başarıyı etkileyen faktörlerden biridir (Mohamed \& Waheed, 2011). Aiken (1970), ortokul öğrencilerinin matematiğe yönelik tutumları ile matematik başarıları arasında yüksek bir ilişki olduğunu, Ma (1997) olumlu tutuma sahip öğrencilerin akademik anlamda daha başarılı olduklarını vurgulamaktadır. Ayrıca alan yazınındaki birçok çalışma matematik başarısı ile tutum arasında güçlü bir ilişki olduğunu destekler niteliktedir (Bramlett \& Herron, 2009; Lipnevich, Preckel \& Krumm, 2016; Ma \& Kishor, 1997; Schenkel, 2009). Ancak, bu durumun aksi sonuçlarının elde edildiği çalışmalarda bulunmaktadır. Örneğin; Peker ve Mirasyedioğlu (2003), yapmış oldukları çalışmada matematiğe yönelik tutum ile başarı arasındaki ilişkinin düşük düzeyde olduğu sonucuna ulaşılmıştır. Öğrenme süreci içinde büyük önem taşıyan matematiğe karşı tutum, etkili bir biçimde ölçülmesi gerekir (Nazlıçiçek \& Erktin, 2002). Çünkü, matematiğe yönelik tutum, birey tarafından inanç ve tecrübe ile kazanılan, ancak değiştirilebilen bir tavırdır (Eshun, 2004). Matematik dersine yönelik tutumun ölçülebilir olması bu nedenle tespit edilen eksikliklerin belirlenmesi matematik dersine olan başarının atmasında etkili olabilir (Önal, 2013; Yıldız \& Turanl1, 2010).

Matematik alanında yurt dışında ve ülkemizde öğretmen adayları ile öğrencilerin matematiğe yönelik tutumlarını belirlemek amacıyla pek çok tutum ölçeği geliştirme çalışmasının yapıldığı görülmektedir. Örneğin; Erol (1989), lise öğrencilerinin matematiğe karşı tutumunu ölçmeye yönelik 70 madde, 6 boyut, 4'lü likert tipi; Aşkar (1986), öğrencilerin matematik dersine yönelik tutumunu ölçmek amaçli 20 maddeden (10 olumlu, 10 olumsuz) oluşan 5'li likert tipi; Duatepe \& Çilesiz (1999), üniversite öğrencilerinin matematik dersine yönelik tutumlarını saplamak amaçlı 38 madde, 4 boyut, 5 'li likert tipi; Turanlı, Karakaş-Türker \& Keçeli (2008), eğitim fakülteleri müferadatı içerisinde yer alan matematik alan derslerine ilişkin tutumu belirlemeye yönelik 20 madde tek boyutlu; Gülten \& Derelioğlu (2006), öğretmenlerin matematik öğretmeye ilişkin tutumlarını ölçen 32 madde, 4 faktörlü; ortaokul öğrencileri için Önal (2013), 22 madde, 4 faktör, 5'li likert tipi matematik tutum ölçeği; KarakaşTürker \& Turanlı (2008), matematik öğretmen adaylarının matematik eğitimi derslerine yönelik tutumlarını belirlemek amaçlı 18 madde, tek faktör, 5'li likert tipi, Demir (2004), sınıf öğretmeni adaylarının tutumlarını belirlemek amacıyla 32 madde, 3 faktör; Cansız-Aktaş \& Aktaş (2013), lise öğrencilerinin geometriye yönelik tutumlarını belirlemek amacıyla 24 madde, 4 faktör, 5'li likert tipi; Bulut, Ekici, İşler \& Helvacı (2002) bireylerin geometri dersine yönelik tutumlarını geliştirmek amaçlı 17 madde, 3 faktör, 5'li likert tipi; Duatepe \& Ubuz (2007), ortaokul öğrencilerinin geometri dersine yönelik tutumlarını belirlemeye yönelik 12 madde, 2 boyut, 5‘li likert tipi; Bal \& Karacaoğlu (2015), ortaokul öğrencilerinin cebir konusuna yönelik tutumlarını belirlemek amaçlı 25 madde, 2 faktör, 5'li likert tipi şeklinde ölçek geliştirme çalışmaları gerçekleştirmişlerdir.

Yurt dişında, tutum ölçeği geliştirme çalışmalarından 108 madde, 9 faktörden oluşan Fennema-Sherman (1976) matematik tutum ölçeği kullanılarak yapılan araştırmaların çoğunlukta olduğu dikkat çekmektedir (Tapia \& March, 2004). Ayrıca matematiğe yönelik tutum ölçeği geliştirme çalışmaları (Adelson \& McCoach, 2011; Aiken \& Dreger, 1961, 1974; Michaels \& Forsyth, 1977; Palacios, Arias \& Arias, 2014; Tahar, Ismail, Zamani \& Adnan, 2010) literatürde yer almaktadır. Bunun yanında farklı ülkelerde geliştirilmiş olan tutum ölçeklerinin dilimize uyarlama çalışmaları mevcuttur. Örneğin; Tabuk \& Hacıömeroğlu (2015), Tapia (1996) 
tarafindan geliştirilen ve Haciömeroğlu (2017), Lim ve Chapman (2013) tarafindan uyarlaması yeniden yapılan tutum ölçeklerinin geçerlilik ve güvenirlilik çalışmalarını yapmışlardır.

$\mathrm{Bu}$ araştırmada, Yáñez-Marquina \& Villardón-Gallego (2016) tarafindan geliştirilen “Ortaokul Öğrencileri için Matematiğe Yönelik Tutum Ölçeği (Scale for Assessing Attitudes towards Mathematics in Secondary Education (SATMAS)'”nin Türkçe'ye uyarlanması hedeflenmiştir. Genel olarak bakıldığında özellikle ortaokul öğrencilerine yönelik olarak hazırlanmış tutum ölçeği çalışmalarının oldukça az olduğu dikkat çekmektedir. Böylelikle ortaokul öğrencilerinin matematiğe yönelik tutumlarını ölçen geçerli ve güvenilir alternatif bir ölçme aracını Türkçe’ye uyarlanarak literatüre kazandırılması amaçlanmaktadır.

\section{Yöntem}

Araştırmada, tarama modeli kullanılmıştır. Geçmişi veya mevcut durumu olduğu gibi betimlemeyi hedefleyen tarama modelinde, evrenin tümü veya evrenden alınacak bir grup üzerinden genel bir yargıya varmak hedeflenmektedir (Karasar, 2005).

\section{Çalışma Grubu}

Çalışmanın verileri, 2017-2018 eğitim öğretim yılının ikinci yarısında üç farklı ortaokulun $5,6,7$ ve 8 . sınıfinda öğrenimine devam öğrencilerinden toplanmıştır. Kolay ulaşılabilir örnekleme yönteminin temel alındığı araştırmaya 465 (\%53) kız ve 413 (\%47) erkek olmak üzere 878 ortaokul öğrencisi katılmıştır. Aşağıdaki Tablo 1'de çalışmaya katılan öğrencilerin demografik bilgileri yer almaktadır.

Tablo 1. Katılımcılara Ait Demografik Özellikler

\begin{tabular}{lcc}
\hline Sinıf düzeyi & F & \% \\
\hline 5. sinıf & 148 & 16,9 \\
6. sinıf & 279 & 31,8 \\
7. sinıf & 252 & 28,7 \\
8. sinıf & 199 & 22,6 \\
\hline Toplam & 878 & 100 \\
\hline Cinsiyet & & \\
\hline Kiz & 465 & 53 \\
Erkek & 413 & 47 \\
\hline Toplam & 878 & 100 \\
\hline
\end{tabular}

Katılımcı öğrencilerin \%16,9 $(n=148)$ u beş, \%31,8 $(n=279)$ i altı, \%28,7 $(n=252)$ si yedi ve \%22,6 ( $\mathrm{n}=199)$ sı sekizinci sınıfta öğrenim görmektedir. Açıklayıcı faktör analizi için 320, doğrulayıcı faktör analizi için 344 ve geçerlilik çalışması için 214 ortaokul öğrencisinden alınan veriler kullanılmıştır.

\section{Ölçeğin Özgün Formu}

Ölçeğin özgün formu öz benlik, matematiğin algılan kullanışlılığı ve ilgi olmak üzere üç boyuttan oluşmaktadır. Ölçeğin orijinal formu yaş ortalamaları 13,96 (sd=1.09) olan 792 ortaokul öğrencisine uygulanarak geliştirilmiştir. Ölçeğin bütünü için Cronbach alfa katsayısı .92 olarak bulunmuştur. Ölçekte, katılımcılar her maddeye katılma derecesine göre 0 (kesinlikle katılmıyorum) ile 10 (kesinlikle katılıyorum) arasında puanlar vermektedir.

Öz benlik (Student's math self-concept): Matematiği öğrenme ve kullanma becerisine ilişkin öğrencilerin düzeylerini belirler (ör. Matematik problemlerini çözemiyorum). Bu boyuttan 
yüksek puan alan öğrenci matematik ile ilgili görevleri anlama ve çözme yeteneğine sahip iken düşük puan alan bir öğrencinin ise matematiği anlama ve yapma kabiliyetinin düşük olduğu düşünülür.

Matematiğin algılan kullanışlılığı (Perceived usefulness of mathematics): Öğrencilerin matematiğe olan dış kaynaklı değerini ölçer. Bu boyut, öğrencilerin mevcut ve gelecekteki hedeflerinin yanı sıra okul, meslek ve günlük hayatla ilgili olarak matematiğin uygulanabilirliği hakkındaki inançlarını ölçmektedir (ör. Matematiği öğrenmek, gelecekteki kariyerim için önemlidir.). Bu nedenle, bu boyutta yüksek puan alan bir öğrenci hem mevcut hem de gelecekteki hedefleri için matematiği çok yararlı buluyor iken düşük puan alan bir öğrenci hem şimdiki hem de gelecekteki hedefleri için matematiğin faydasına inanmamaktadır.

İlgi (Interest for mathematics): Öğrencilerin matematik öğrenmek için sahip oldukları ilgi düzeylerini belirtir (ör. Matematik problemlerini çözerken zaman hızlı geçiyor.). Bu boyuttan yüksek puan alan bir öğrenci, matematik öğrenmeye büyük ilgi duyar. Diğer taraftan, düşük puan alan bir öğrenci, matematik öğrenmeyi zevkli değil, sıkıcı bulmaktadır (Yáñez-Marquina \& Villardón-Gallego, 2016).

Ölçeğin uyarlama çalışmasına başlamadan önce yazarla iletişime geçilerek yapılacak çalışma için gerekli izin alınmıştır. Çalışmasının ilk aşamasında ölçek Türkçe'ye çevrilmiştir. Bu amaçla, alanında uzman iki matematik eğitimcisi, bir matematik öğretmeni ve iki İngiliz dili eğitimi alanında eğitmen olmak üzere beş kişilik grup uyarlama çalışmasına katılmıştır. Bu çalışma sırasında, çalışma grubu ölçeğin özgün şekline dikkat ederek ifadelerin açık ve anlaşılır olması için gerekli özeni göstermeyi amaçlamıştır. Uzman grubunun yaptığı çalışmalarda uyuşmanın sağlandığı noktada ölçek maddelerine son hali verilerek en uygun çeviri formu elde edilmiştir. Son olarak ölçek maddelerindeki yazım, noktalama ve anlam bakımdan düzenlemeleri yapması için alanında uzman bir Türkçe öğretmeninin görüşleri alınarak ölçeğe son hali verilmiştir.

\section{Bulgular}

\section{Açımlayıcı Faktör Analiz Sonuçları}

“Ortaokul Öğrencileri için Matematiğe Yönelik Tutum Ölçeği” nin faktör analizinin yapılabilmesi için öncelikle örneklem büyüklüğünün yeterli sayıda olup olmadığının anlaşılması gerekmektedir (Çokluk, Şekercioğlu \& Büyüköztürk, 2016). Bu amaçla Kaiser-Meyer-Olkin (KMO) katsayısı hesaplanmış ve bu değer .91 olarak bulunmuştur. KMO değerinin .90 üzerinde olması "mükemmel" olarak yorumlanmaktadır (Çokluk ve ark, 2016). Bartlett küresellik testi

sonucundan $\left[\chi^{2}=3669.296 ; \mathrm{sd}=171 ; \mathrm{p}=0.000<0.1\right]$ elde edilmiştir. KMO değerinin .60 dan yüksek olması ve Bartlett testinin anlamlı çıkması verilerin faktör analizi için uygun olduğunu anlamına gelir (Büyüköztürk, 2006). Bu bulgular, ölçeğin faktör analizi için uygun olduğu göstermektedir.

Açımlayıcı faktör analizi sonuçları incelendiğinde uyarlaması yapılan ölçeğin orijinalinde olduğu gibi özdeğeri 1'den büyük olan üç faktör altında toplandığını göstermiştir. Tüm maddelerin faktör yük değerlerinin .32 nin üzerinde olduğu ancak 19. maddenin faktör yük değeri .393 ve iki farklı faktör altında binişik olduğu sonucua ulaşılmıştır. 19. madde için yük değerleri arasında fark .1'den (.457-.421=.036) küçük olduğundan analize bu madde dışarıda bırakılarak 
devam edilmiştir. Faktörler için öz değer sonuçları 7.409; 2.763; 1.815 şeklindedir. Açıkladıkları varyans miktarları birinci faktör tek başına toplam varyansın $\% 41,15$ 'i, birinci ve ikinci faktörler \%56,50'sini, üç faktör toplam varyansın \%66,59'unu açıklamaktadır. Aşağıdaki Tablo 2 ölçeğin faktör yükleri ve madde-toplam korelâsyonu hakkında bilgileri sunmaktadır.

Tablo 2. "Ortaokul Öğrencileri için Matematiğe Yönelik Tutum Ölçeği” Faktör Yükleri ve MaddeToplam Korelâsyonu

\begin{tabular}{|c|c|c|c|c|c|}
\hline $\begin{array}{l}\text { Madde } \\
\text { No }\end{array}$ & $\begin{array}{l}\text { İfadeler } \\
\end{array}$ & Faktör 1 & Faktör 2 & Faktör 3 & $\begin{array}{l}\text { Madde } \\
\text { Toplam } \\
\text { Korelâsyon }\end{array}$ \\
\hline $\mathrm{m} 15$ & $\begin{array}{l}\text { Matematik çalışırken zamanın nasıl geçtiğini } \\
\text { anlamıyorum. }\end{array}$ & .830 & & & .580 \\
\hline $\mathrm{m} 16$ & Matematik çalışmak eğlencelidir. & .788 & & & .713 \\
\hline $\mathrm{m} 17$ & $\begin{array}{l}\text { Matematik problemlerini çözerken zaman hızlı } \\
\text { geçiyor. }\end{array}$ & 762 & & & .519 \\
\hline $\mathrm{m} 13$ & Matematik çalışmayı seviyorum. & .754 & & & .793 \\
\hline $\mathrm{m} 18$ & Matematik eğlencelidir. & .721 & & & .759 \\
\hline $\mathrm{m} 14$ & Matematiği seviyorum. & 626 & & & .790 \\
\hline $\mathrm{m} 2$ & $\begin{array}{l}\text { Çok fazla çaba sarf etmeme rağmen matematiği } \\
\text { anlayamıyorum. }\end{array}$ & & .848 & & .657 \\
\hline $\mathrm{m} 6$ & $\begin{array}{l}\text { Ne yaparsam yapayım, matematikten düşük not } \\
\text { alıyorum. }\end{array}$ & & .794 & & .633 \\
\hline $\mathrm{m} 7$ & $\begin{array}{l}\text { Matematik öğrenmek bana her zaman zor } \\
\text { gelmiştir. }\end{array}$ & & .794 & & 706 \\
\hline $\mathrm{m} 1$ & $\begin{array}{l}\text { Sinıf arkadaşlarımla matematik problemleri ve } \\
\text { sorularını çözerken kendimi onlara göre daha } \\
\text { yeteneksiz hissediyorum. }\end{array}$ & & .789 & & .554 \\
\hline m5 & Matematik problemlerini çözemiyorum. & & .734 & & .609 \\
\hline $\mathrm{m} 3$ & Matematik zor bir derstir. & & .732 & & .657 \\
\hline $\mathrm{m} 4$ & $\begin{array}{l}\text { Matematik öğrenmeye yetenekli olduğumu } \\
\text { düşünmüyorum. }\end{array}$ & & .676 & & 664 \\
\hline $\mathrm{m} 9$ & Her insanın matematik öğrenmeye ihtiyacı vardır. & & & .848 & .550 \\
\hline $\mathrm{m} 11$ & Toplumların gelişmesi için matematik önemlidir. & & & .837 & .560 \\
\hline $\mathrm{m} 10$ & Yaşam için matematik gereklidir. & & & .779 & .569 \\
\hline $\mathrm{m} 12$ & $\begin{array}{l}\text { Matematiği öğrenmek, gelecekteki kariyerim için } \\
\text { önemlidir. }\end{array}$ & & & .651 & .473 \\
\hline \multirow[t]{3}{*}{$\mathrm{m} 8$} & Matematik yararlı bir derstir. & & & .746 & .649 \\
\hline & Özdeğerler & 7.409 & 2.763 & 1.815 & \\
\hline & Açıklanan toplam varyans (\%) & 41.15 & 56.50 & 66.59 & \\
\hline
\end{tabular}

Tablo 2 incelendiğinde ölçekteki madde faktör yük değerleri .62 ile .84 arasında değişmektedir. Madde faktör yük değerleri .40 ve üzeri "çok iyi", .70 ve üzeri "mükemmel" olarak değerlendirilir (Tabachnick \& Fidell, 2001). Bu durumda, maddelere ait faktörler yük değerleri arasında güçlü ilişki olduğunu söylenebilir.

\section{Doğrulayıcı Faktör Analizi Sonuçları}

Ölçek geliştirme ve geçerlilik çalışmalarında doğrulayıcı faktör analizine başvurulmaktadır. Doğrulayıcı faktör anlizinde amaç, önceden belirli yada kurgulanmış bir yapıyı doğrulamaktır 
(Bayram, 2016). Doğrulayıcı faktör analizi sonuçlarına göre ölçeğin uyum indeksleri [ $\chi^{2}=$ 347.740; $\mathrm{sd}=132, \mathrm{p}=.000 ; \chi^{2} \div \mathrm{sd}=2.634 ; \mathrm{CFI}=.951 ; \mathrm{GFI}=.902 ; \mathrm{NFI}=.923 ; \mathrm{AGFI}=.873$; RMSEA = .069 ] olarak hesaplanmıştır. Kabul gören uyum indeksi kriterlerine bakıldığında; kikare değerinin serbestlik dercesine oranı 2.634 olarak bulunmuştur. Ki-kare değerinin serbestlik derecesine oranının 3'ten küçük olması mükemmel uyum olarak kabul edilmektedir (Kline, 2005). CFI değerinin $\geq .95$ olması mükemmel, NFI değerinin $\geq .90$ olması iyi uyum (Tabachnick \& Fidell, 2001) ve GFI değerinin $\geq .90$ olması iyi uyum olduğunu göstermektedir (Sümer, 2000). Buna göre .951 olarak hesaplanan CFI değeri mükemmel, .923 olarak hesaplanan NFI değeri iyi ve .902 olarak hesaplanan GFI değerinin iyi düzeyde uyum gösterdiği söylenebilir. RMSEA değerinin 0.05 ile 0.08 arasında olması kabul edilebilir uyum olduğunu göstermektedir (Büyüköztürk, Akgün, Kahveci \& Demirel, 2004). RMSEA değeri .069 olarak hesaplanmış olduğundan kabul edilebilir olduğu söylenebilir. Bu sonuçlara göre üç faktörlü yapıya sahip olan ölçeğin doğrulayıcı faktör analizi için gerekli olan uyum indeks değerlerini sağladığı görülmektedir.

\section{Güvenirlilik Çalışması Sonuçları}

“Ortaokul Öğrencileri için Matematiğe Yönelik Tutum Ölçeğì” nin iç güvenirliğini tespit etmek amacıyla Croncbah alfa iç tutarlılık katsayısı hesaplanmıştır. Bunun için önce ölçeğin madde toplam puan korelasyonuna bakılmıştır. Madde toplam puan korelasyonunun pozitif ve yüksek olması maddelerin benzer davranışları örneklediği ve testin iç tutarlılığının yüksek olduğu anlamına gelmektedir (Büyüköztürk, 2006). Ölçeğin madde toplam korelasyon değerleri ve ölçek faktör puanlarının alt $\% 25$ ve üst \%25'lik gruplar arasındaki farkın anlamlılığına ait ilişki t-testi kullanılarak analiz edilmiştir. Elde edilen sonuçlar aşağıda Tablo 3'de sunulmaktadır.

Tablo 3. "Ortaokul Öğrencileri için Matematiğe Yönelik Tutum Ölçeği” nin Madde Analizi Sonuçları

\begin{tabular}{cccccc}
\hline $\begin{array}{c}\text { Madde } \\
\text { No }\end{array}$ & $\begin{array}{c}\text { Madde } \\
\text { Toplam } \\
\text { Korelâsyonu }\end{array}$ & $\begin{array}{c}\mathrm{t}(\text { alt \%25- } \\
\text { üst \%25) }\end{array}$ & $\begin{array}{c}\text { Madde } \\
\text { No }\end{array}$ & $\begin{array}{c}\text { Madde } \\
\text { Toplam } \\
\text { Korelâsyonu }\end{array}$ & $\begin{array}{c}\mathrm{t}(\text { alt\%25- } \\
\text { üst\%25) }\end{array}$ \\
\hline $\mathrm{m} 1$ & .622 & $-12.80^{*}$ & $\mathrm{~m} 10$ & .683 & $-13.58^{*}$ \\
$\mathrm{~m} 2$ & .695 & $-13.48^{*}$ & $\mathrm{~m} 11$ & .701 & $-13.68^{*}$ \\
$\mathrm{~m} 3$ & .730 & $-15.00^{*}$ & $\mathrm{~m} 12$ & .671 & $-12.20^{*}$ \\
$\mathrm{~m} 4$ & .698 & $-13.19^{*}$ & $\mathrm{~m} 13$ & .784 & $-16.23^{*}$ \\
$\mathrm{~m} 5$ & .670 & $-12.27^{*}$ & $\mathrm{~m} 14$ & .812 & $-18.76^{*}$ \\
$\mathrm{~m} 6$ & .647 & $-13.14^{*}$ & $\mathrm{~m} 15$ & .447 & $-9.41^{*}$ \\
$\mathrm{~m} 7$ & .618 & $-10.61^{*}$ & $\mathrm{~m} 16$ & .754 & $-16.16^{*}$ \\
$\mathrm{~m} 8$ & .752 & $-14.81^{*}$ & $\mathrm{~m} 17$ & .516 & $-9.45^{*}$ \\
$\mathrm{~m} 9$ & .688 & $-13.21^{*}$ & $\mathrm{~m} 18$ & .745 & $-16.45^{*}$ \\
\hline${ }^{*} \mathrm{p}<001$ & & & & &
\end{tabular}

Tablo 3'ü değerlendirildiğinde ölçek maddeleri için madde toplam korelasyonunun 447 ile .812 arasında değiştiği ve alt \%25-üst \%25'lik grupların puan ortalaması arasında yapılan t testi sonuçlarının tüm maddeler için anlamlı $(\mathrm{p}<.001)$ olduğunu görülmektedir. Ölçeğin tamamı için Cronbach alfa iç tutarlılık katsayısı .91 olarak hesaplanmış olup orijinal ölçeğin Cronbach alfa iç tutarlılık katsayısı .92'dir. Ölçeğin “Öz benlik" alt boyutunda 7 madde $(1 ; 2 ; 3 ; 4 ; 5 ; 6 ; 7)$, "Matematiğin algılan kullanışlılığı" alt boyutunda 5 madde $(8 ; 9 ; 10 ; 11 ; 12)$ ve "İlgi" alt boyutunda 6 madde $(13 ; 14 ; 15 ; 16 ; 17 ; 18)$ bulunmaktadır. Çalışma sonucunda ölçeğin alt boyutları için sırasıyla Cronbach alfa iç tutarlılık katsayıları .89; .87; .89 olarak hesaplanmıştır. 


\section{Sonuç ve Tartışma}

Bu çalışmada Yáñez-Marquina \& Villardón-Gallego (2016) tarafindan geliştirilen “Ortaokul Öğrencileri için Matematiğe Yönelik Tutum Ölçeği”' Türkçe'ye uyarlayarak ortaokul öğrencileri için kullanışlı, geçerli ve güvenilir bir tutum ölçeği geliştirme çalışması yapılmıştır. Açımlayıcı faktör analizine ölçeğin yapı geçerliliğini incelemek amacıyla başvurulmuştur. Özgün ölçekte yer alan 19. madde iki farklı faktör altında binişik olduğundan ölçekten çıkarılarak analize 18 madde üzerinden devam edilmiştir. Açımlayıcı faktör analizi sonuçları ölçeğin özgün ölçekle uyuşan faktör yapısında olduğunu göstermiştir. Doğrulaycı faktör analizi, modelin uyum indeks değerlerinin literatürde aranan niteliklerde olduğu ve iyi düzeyde uyum sağladığı sonucunu göstermiştir. Ölçekte yer alan maddelerin ortaokul öğrencilerinin matematiğe yönelik tutum bakımından ne derece ayırt ettiğini değerlendirmek amacıyla, ölçek faktör puanlarına göre alt $\% 25$ ve üst \%25 'lik puan aralığındakilerin madde puan ortalaması arasındaki farkın ilşkisiz ttesti sonucu tüm maddelerin $\mathrm{p}<.001$ için anlamlı bulunmuştur.

Analizler, ölçeğin özgün hali ile örtüşen öz benlik (7 madde), matematiğin algılan kullanışlılığı (5 madde) ve ilgi (6 madde) olmak üzere, üç faktörlü bir yapıda olduğunu göstermiştir. Önal (2013) in ortaokul öğrencileri için geliştirdiği ölçek ilgi, kayg1, çalışma ve gereklilik alt boyutlarını içermektedir. Bu çalışmada uyarlaması yapılan ölçek ise farklı alt boyutları içermektedir. Böylelikle ortaokul seviyesindeki öğrencilerin matematiğe yönelik tutumlarını etkileyebilecek olan faktörler farklı boyutlar dikkate alarak değerlendirilebilecektir. Yáñez-Marquina ve Villardón-Gallego (2016), ölçeğin güvenirlik ve geçerlik sonuçlarını göz önüne aldıklarında, ortaokul öğrencilerinin matematiğe yönelik tutumlarını değerlendirmek için umut verici bir araç olduğu söylemektedirler. Bu sonucun Türkçe'ye uyarlaması yapılan ölçek için de geçerli olduğu söylenebilir. Bu bakımdan uyarlaması gerçekleştirilen bu ölçeğin öğrencilerimiz için uygulanması kolay olması, zaman almaması ve maddelerinin anlaşılır olması açısından literatüre katkı sağlayacağı söylenebilir. Öğrencilerin matematiğe karşı tutumlarını etkileyen pek çok faktör bulunmaktadır. Arıcı (2013), öğrencilerin matematik dersine yönelik tutumlarının belirlenmesinde hangi etmenlerin etkili olduğunun tespit edilmesinin, öğrencilerin olumlu tutum geliştirme çabalarına yardımcı olacağını belirtmektedir. Katrancı ve Şengül (2019), tutumları değiştirmek için eğitimin önemli bir araç olduğunu belirtmek ile birlikte öğrenci tutumlarını ve nasıl ölçmemiz gerektiğini bilmek eğitimin kalitesini artırmakta etkili olduğuna vurgu yapmaktadırlar. Bu açıdan bakıldığında, ölçeğin alt faktörlerinin incelemiş olduğu yapıların öğrencilerin matematiğe olan tutumlarının tespitinde önemli rol oynayacağı düşünülmektedir.

Toplam 18 maddeden oluşan ölçeğin Türkçe'ye uyarlanmış halinin Cronbach alfa katsayısı .91 olarak hesaplanmış olması ölçeğin güvenilir bir yapıya sahip olduğunu göstermektedir. Sonuç olarak, Türkçe’ye uyarlanan “Ortaokul Öğrencileri için Matematiğe Yönelik Tutum Ölçeği” nin ortaokul öğrencileri için geçerli ve güvenilir bir ölçme aracı olduğu sonucu elde edilmiştir. 


\section{Kaynakça}

Adelson, J. L. \& McCoach, D. B. (2011). Development and psychometric properties of the math and me survey: Measuring third through sixth graders' attitudes toward mathematics. Measurement and Evaluation in Counseling and Development, 44(4), 225247.

Aiken, L. R. Jr. (1970). Attitudes toward mathematics. Review of Educational Research, 40(4), 551-596.

Aiken L. R. \& Dreger, R. M. (1961). The effect of attitudes on performance in mathematics. Journal of Educational psychology, 52(1), 19-24.

Akinoso, S. O. (2017). Students attitude to mathematics as correlates to attitude and performance in chemistry. The Eurasia Proceedings of Educational \& Social Sciences (EPESS), 8, 4045 .

Arıcı, Ö. (2013). Öğretmen görüşlerine göre öğrencilerin matematik dersine yönelik tutumlarını etkileyen faktörlerin ölçeklenmesi çalışması. Ege Eğitim Dergisi, 14(2), 25-40.

Aşkar, P. (1986). Matematik dersine yönelik tutumu ölçen likert-tipi bir ölçeğin geliştirilmesi. Eğitim ve Bilim, 11(62), 31-36.

Bal, A. P. \& Karacaoğlu, A. (2105). An attitude scale improving study in the context of elementary school algebra course. Eğitimde Kuram ve Uygulama, 11(4), 1258-1271.

Bayram, N. (2016). Yapısal Eşitlik Modellemesine Giriş Amos Uygulamaları. Bursa: Ezgi.

Bohner, G., \& Wänke, M. (2002). Attitudes and Attitude Change. Psychology Press.

Bramlett, D. C. \& Herron, S. (2009). A study of African-American College students' attitude towards mathematics. Journal of Mathematical Sciences \& Mathematics Education, 4(2), 43-51.

Bulut, S., Ekici, C., İşler, A. İ. \& Helvacı, E. (2002). Geometriye yönelik bir tutum ölçeği. Eğitim ve Bilim, 27(125), 3-7.

Büyüköztürk, Ş. (2006). İstatistik, Araştırma Deseni SPSS Uygulamaları ve Yorum. Ankara: Pegem Akademi.

Büyüköztürk, Ş., Akgün, Ö. E., Kahveci, Ö. \& Demirel, F. (2004). Güdülenme ve öğrenme stratejileri ölçeğinin Türkçe formunun geçerlik ve güvenirlik çalışması. Kuram ve Uygulamada Ĕ̈itim Bilimleri, 4(2), 207-239.

Cansız-Aktaş, M. \& Aktaş, D. Y. (2013). The development of a current attitude scale towards geometry. Necatibey Eğitim Fakültesi Elektronik Fen ve Matematik Dergisi, 7(2), 225-247.

Çokluk, Ö., Şekercioğlu, G. \& Büyüköztürk, Ş. (2016). Sosyal Bilimler için Çok Değişkenli Istatistik: Spss Ve Lisrel Uygulamaları (4. bask1). Ankara: Pegem Akademi.

Demir, M. K. (2004). Sınıf öğretmeni adaylarının matematik tutumlarının incelenmesi. Eurasian Journal of Educational Research, 14, 162-170.

Duatepe, A. \& Çilesiz, Ş. (1999). Matematik tutum ölçeği geliştirilmesi. Hacettepe Üniversitesi Eğitim Fakültesi Dergisi, 16(17), 45-52. 
Duatepe, A., Ubuz, B. (2007). The development of a geometry attitude scale. Academic Exchange Quarterly, 11(2), 679-685.

Erol, E. (1989). Prevalence and correlates of math anxiety in Turkish high school students. Yayınlanmamış Yüksek Lisans Tezi. Boğaziçi Üniversitesi, İstanbul.

Eshun, B. (2004). Sex-differences in attitude of students towards mathematics in secondary schools. Mathematics Connection, 4(1), 1-13.

Farooq, M. S. \& Shah, S. Z. U. (2008). Students' attitude towards mathematics. Pakistan Economic and Social Review, 46(1), 75-83.

Gülten D. Ç. \& Derelioğlu, Y. (2006). Öğretmen adaylarının matematik öğrenmeyi öğretmeye ilişkin tutumlarını incelemeye yönelik bir ölçek geliştirme çalışması. Eurasian Journal of Educational Research, 24, 103-111.

Hacıömeroğlu, G. (2017). Reliability and validity study of the attitude towards mathematics instruments short form. Journal of Computer and Education Research, 5(9), 84-99.

Karakaş-Türker, N. \& Turanl1, N. (2008). Matematik eğitimi derslerine yönelik tutum ölçeği geliştirilmesi. Gazi Eğitim Fakültesi Dergisi, 28(3), 17-29.

Karasar, N. (2005) Bilimsel Araştırma Yöntemleri. Ankara: Nobel Yayın.

Katrancı, Y., \& Şengül, S. (2019). Ortaokul öğrencilerinin matematik problemi oluşturma, matematik problemi çözme ve matematiğe yönelik tutumları arasındaki ilişkiler. Ĕgitim ve Bilim, 44(197),1-24.

Kline, R. B. (2005). Principles And Practice Of Structural Equation Modeling. New York: Guilford Publications, Inc.

Kocakaya, S., Okuyucu, M. A., Öner, M. \& UzunyoL, B. (2018). Ortaokul öğrencilerinin matematiğe yönelik tutumlarına etki eden değişkenlerin yapısal eşitlik modeli ile incelenmesi. Yüzüncü Yll Üniversitesi Eğitim Fakültesi Dergisi, 15(1), 495-524.

Lipnevich, A. A., Preckel, F. \& Krumm, S. (2016). Mathematics attitudes and their unique contribution to achievement: Going over and above cognitive ability and personality. Learning and Individual Differences, 47, 70-79.

Ma, X. (1997). Reciprocal relationships between attitude toward mathematics and achievement in mathematics. The Journal of Educational Research, 90(4), 221-229.

Ma, X. \& Kishor, N. (1997). Assessing the relationship between attitude toward mathematics and achievement in mathematics: A meta-analysis. Journal for Research in Mathematics education, 28(1), 26-47.

MEB (2009). İlköğretim Matematik Dersi 6-8. Sınıflar Öğretim Programı.

MEB (2013). Ortaokul Matematik Dersi (5, 6, 7 ve 8. Sınıflar) Öğretim Programı.

MEB (2017). Matematik Dersi Öğretim Programı (İlkokul ve Ortaokul 1, 2, 3, 4, 5, 6, 7 ve 8. Siniflar). 
Michaels, L. A. \& Forsyth, R. A. (1977). Construction and validation of an instrument measuring certain attitudes toward mathematics. Educational and Psychological Measurement, 37(4), 1043-1049.

Moenikia, M. \& Zahed-Babelan, A. (2010). A study of simple and multiple relations between mathematics attitude, academic motivation and intelligence quotient with mathematics achievement. Procedia-Social and Behavioral Sciences, 2, 1537-1542.

Mohamed, L. \& Waheed, H. (2011). Secondary students' attitude towards mathematics in a selected school of Maldives. International Journal of Humanities and Social Science, 1(15), 277-281.

Nazlıçiçek, N. \& Erktin, E. (2002). İlköğretim matematik öğretmenleri için kısaltılmış, matematik tutum ölçeği. V. Ulusal Fen Bilimleri ve Matematik Eğitimi Kongresi Bildiriler Kitabı, 860865.

Önal, N. (2013). Ortaokul öğrencilerinin matematik tutumlarına yönelik ölçek geliştirme çalışması. Illköğretim Online, 12(4), 938-948.

Palacios, A., Arias, V. \& Arias, B. (2014). Attitudes towards mathematics: Construction and validation of a measurement instrument. Revista de Psicodidáctica, 19(1), 67-91.

Peker, M. \& Mirasyedioğlu, S., (2003). Lise 2. sınıf öğrencilerinin matematik dersine yönelik tutumları ve başarıları arasındaki ilişki. Pamukkale Üniversitesi Eğitim Fakültesi Dergisi, 2(14), 157-166.

Schenkel, B. D. (2009). The impact of an attitude toward mathematics on mathematics performance. Doctoral dissertation, Marietta College.

Sezgin-Memnun, D. (2015). Ortaokul beşinci ve altıncı sınıf öğrencilerinin matematik hakkındaki inanç ve tutumlarının nitel ve nicel analizi. Journal of Kirsehir Education Faculty, 16(2), 23-42.

Soni, A. \& Kumari, S. (2017). The role of parental math anxiety and math attitude in their children's math achievement. International Journal of Science and Mathematics Education, 15(2), 331-347.

Sümer, N. (2000). Yapısal eşitlik modelleri: Temel kavramlar ve örnek uygulamalar. Türk Psikoloji Yazılarl, 3(6), 49-73.

Tabachnick, B. G. \& Fidell, L. S. (2001). Using Multivariate Statistcs. Boston: Ally and Bacom.

Tabuk M. \& Haciömeroğlu, G. (2015). Turkish adaptation of attitude towards mathematics instrument. Eğitimde Kuram ve Uygulama, 11(1), 245-260.

Tahar, N. F., Ismail, Z., Zamani, N. D. \& Adnan, N. (2010). Students' attitude toward mathematics: The use of factor analysis in determining the criteria. Procedia-Social and Behavioral Sciences, 8, 476-481.

Tapia, M., \& Marsh, G. E. (2004). An instrument to measure mathematics attitudes. Academic Exchange Quarterly, 8(2), 16-22.

Tavşancıl, E. (2010). Tutumların Ölçülmesi ve SPSS ile Veri Analizi (4. bask1). Ankara: Nobel Yayın. 
Turanl, N., Karakaş-Türker, N. \& Keçeli, V. (2008). Matematik alan derslerine yönelik tutum ölçeği geliştirilmesi. Hacettepe Üniversitesi Eğitim Fakültesi Dergisi, 34, 254-262.

Ünal, C. (1981). Genel Tutumların veya Değerlerin Psikolojisi Üzerine Bir Araştırma. Ankara: Ankara Üniversitesi Dil Tarih ve Coğrafya Fakültesi Yayını.

Yáñez-Marquina, L. \& Villardón-Gallego, L. (2016). Attitudes towards mathematics at secondary level: Development and structural validation of the scale for assessing attitudes towards mathematics in secondary education (SATMAS). Electronic Journal of Research in Educational Psychology, 14(3), 557-581.

Yıldız, S. \& Turanlı, N. (2010). Öğrenci seçme sınavına hazırlanan öğrencilerin matematik dersine yönelik tutumlarının belirlenmesi. Selçuk Üniversitesi Ahmet Keleşoğlu Eğitim Fakültesi Dergisi, 30, 361-377. 